KNHANES ( $\mathrm{N}=22,948$, estimated population size $=48,402,221)$. We analyzed the prevalence of RA and abnormal status of lipid profiles using general linear model and logistic regression with complex sample design method adjusted by age and sex and evaluated the association between RA and dyslipidemia including nutritional intake data.

Results: The prevalence of RA was $1.21 \%$ [95\% Cl: 1.07-1.38]. The prevalence of dyslipidemia with RA (3.31\% [95\% Cl: 2.63-4.17]) was significantly increased compared with that of dyslipidemia without RA $(1.37 \%$ [95\% Cl: $1.17-1.59]$, $\mathrm{p}<0.001)$

LDL (RA vs. control: $117.77 \pm 3.87 \mathrm{mg} / \mathrm{dL}$ vs. $114.47 \pm 0.51 \mathrm{mg} / \mathrm{dL}, \mathrm{p}<0.001$ ) was significantly increased, whereas TG (RA vs. control: $129.21 \pm 6.38 \mathrm{mg} / \mathrm{dL}$ vs. $136.72 \pm 1.20 \mathrm{mg} / \mathrm{dL}, \mathrm{p}<0.001)$ was significantly decreased in RA. Total cholesterol tended to be higher in RA (RA vs. control: $198.12 \pm 3.09 \mathrm{mg} / \mathrm{dL}$ vs. 188.11 $\pm 0.39 \mathrm{mg} / \mathrm{dL}, \mathrm{p}=0.051$ ). but HDL (RA vs. control: $54.16 \pm 1.42 \mathrm{mg} / \mathrm{dL}$ vs. 52.46 $\pm 0.15 \mathrm{mg} / \mathrm{dL}, \mathrm{p}=0.98$ ) was not different between two groups.

There were no differences in nutritional intake volume including total diet volume, energy intake, water, carbohydrate, protein, fat, other fatty acids and dietary fiber (Table).

Table 1 Nutritional intake difference between RA and control

\begin{tabular}{|c|c|c|c|}
\hline & RA & control & $\mathrm{p}$ \\
\hline \begin{tabular}{|l} 
Total diet $(\mathrm{g} /$ day $)$ \\
\end{tabular} & $1447.96 \pm 55.81$ & $1658.24 \pm 11.50$ & 0.40 \\
\hline Energy intake (kcal/day) & $1826.19 \pm 61.89$ & $2121.24 \pm 12.16$ & 0.87 \\
\hline \begin{tabular}{|l} 
Water (g/day) \\
\end{tabular} & $1027.92 \pm 46.74$ & $1182.23 \pm 9.66$ & 0.38 \\
\hline Protein (g/day) & $61.06 \pm 2.88$ & $74.71 \pm 0.58$ & 0.85 \\
\hline Carbohydrate (g/day) & $298.90 \pm 8.76$ & $318.72 \pm 1.64$ & 0.45 \\
\hline \begin{tabular}{|l} 
Fat $(\mathrm{g} /$ day $)$ \\
\end{tabular} & $36.66 \pm 2.46$ & $47.71 \pm 0.49$ & 0.72 \\
\hline Cholesterol (mg/day) & $207.17 \pm 33.49$ & $278.72 \pm 6.63$ & 0.62 \\
\hline Saturated fatty acid ( $\mathrm{g} /$ day) & $10.05 \pm 0.77$ & $13.75 \pm 0.15$ & 0.95 \\
\hline \begin{tabular}{|l} 
Monounsaturated fatty acid ( $g /$ day) \\
\end{tabular} & $10.97 \pm 0.77$ & $15.17 \pm 0.18$ & 0.86 \\
\hline Polyunsaturated fatty acid (g/day) & $10.08 \pm 0.76$ & $11.94 \pm 0.14$ & 0.88 \\
\hline n-3 fatty acid ( $g /$ day) & $1.59 \pm 0.19$ & $1.70 \pm 0.03$ & 0.46 \\
\hline $\mathrm{n}-6$ fatty acid (g/day) & $8.56 \pm 0.67$ & $10.31 \pm 0.12$ & 0.77 \\
\hline Crude fiber (g/day) & $8.53 \pm 0.71$ & $7.71 \pm 0.09$ & 0.74 \\
\hline \begin{tabular}{|l} 
Dietary fiber (g/day) \\
\end{tabular} & $23.85 \pm 1.62$ & $24.53 \pm 0.30$ & 0.25 \\
\hline
\end{tabular}

Adjusted by age, sex and body mass index

Conclusions: We showed increased prevalence of dyslipidemia patients in the individuals with RA than those without RA. Serum LDL levels was increased and TG was decreased in RA patients of the Korean population survey.

Disclosure of Interest: None declared

DOI: 10.1136/annrheumdis-2018-eular.6695

\section{SAT0158 THE ASSESSMENT OF SAFETY AND EFFICACY OF USING SELF-MONITORING OF DISEASE ACTIVITY VIA WEB PORTAL IN THE MANAGEMENT OF PATIENTS WITH RHEUMATOID ARTHRITIS}

G. Bagirova ${ }^{1}$, E. Lygina ${ }^{1}$, S. lakushin ${ }^{1}$, A. Vorobyev ${ }^{1} .{ }^{1}$ Ryazan State Medical University, Ryazan, Russian Federation

Background: According to the Treat-to-Target guidelines for the RA, the main goal of treatment is remission or, alternatively, a lower activity of the disease. However, persistent remissions and preservation of working capacity are observed in no more than $5-6 \%$ of cases. As a result of the analysis of possible causes of the strategy's lack of efficacy, it seemed to us urgent to create and approve the method of managing RA patients via the "Web portal for self-monitoring of rheumatoid arthritis activity".

Objectives: Maximally quickly identify the exacerbation of the disease and timely strengthen the therapy, for more rapid achievement of remission or low disease activity

Methods: The authors created an interactive web portal for self-monitoring of RA activity. The patient management model using this method is that a patient conducts a monthly self-evaluation of the disease activity and transmits this information to his treating doctor in a remote manner via the web portal. The doctor receives information about the patient's health as quickly as possible. In case of worsening and in the absence of any dynamics, according to the patient, he was invited to the center, where this information was verified by a doctor and, if necessary, correction of therapy was made. If, in the patient's opinion, there was an improvement, he did not come to clinic, but continued therapy. During the management of patients with RA using this method (1 year) initially and further regularly clinical, laboratory and radiological monitoring of efficacy and safety was conducted. Currently, 30 women with RA, age 57 (38; 71), who completed the 6month treatment period, are included in the study. All patients underwent a clinical examination, hand and feet X-ray, laboratory tests and assessment of the RA activity by DAS28 index. Initially, all patients were trained by a rheumatologist to carry out a self-assessment of tender and swollen joints according to the original author's technique "Structured curriculum for teaching RA patients self-monitoring of disease activity".

Results: During 6 months, there was a positive dynamics of the course of the disease, the activity of the RA by DAS 28 decreased. Initially, 5 patients $(16.7 \%)$ had high DAS activity, 24 - moderate (80\%), 1- low (3.3\%). After 6 months of treatment 8 patients $(26.7 \%)$ had low activity, $22(73.3 \%)$ achieved remission. The mean value of the DAS 28 index at the time of inclusion was $3.99(2.46 ; 5.78)$ and after 6 months of management $2.175(0.79 ; 4.31)$, a statistically significan decrease (Wilcoxon T-test $=5$ ). Initially, all patients received methotrexate at an average dose of $12.9 \mathrm{mg}(10 \mathrm{mg} ; 30 \mathrm{mg})$, at 6 months of follow-up, the average dose was $14.6 \mathrm{mg}(10 \mathrm{mg} ; 25 \mathrm{mg})$. An increasing the dose of methotrexate was required in $11(36.6 \%)$ patients. Analysis of clinical and laboratory parameters did not reveal statistically significant deviations.

Conclusions: The 6-month period of patient management via the "web portal for self-monitoring of rheumatoid arthritis activity" proved the possibility of achieving remission and low disease activity in all patients.

Disclosure of Interest: None declared

DOI: 10.1136/annrheumdis-2018-eular.7381

\section{SAT0159 THYROID FUNCTION IN EARLY VERSUS ESTABLISHED RHEUMATOID ARTHRITIS}

S. Hannawi ${ }^{1}$, H. Hannawi ${ }^{2}$, I. Al Salmi ${ }^{3} .{ }^{1}$ Rheumatology, ${ }^{2}$ Ministry of Health and Prevention of UAE, Dubai, United Arab Emirates, ${ }^{3}$ The Royal Hospital, Muscat, Oman

Background: Thyroid dysfunction is common in rheumatoid arthritis (RA). Subclinical hypothyroidism is the first most common, followed by clinical hypothyroidism. Thyroid dysfunction in RA had been found to increase the risk of cardiovascular disease. Subclinical hypothyroidism is defined as increased serum TSH concentration with normal serum free thyroxine (T4) level.

Objectives: The aim of this study was to compare the thyroid function in early RA patients (of less than one-year duration of RA symptoms) versus established RA patients (of more than or equal to one-year duration of RA symptoms)

Methods: We recruited 35 early RA patients (ERA) and 52 established RA patients attending specialized rheumatology clinic. All the patients had no clinical evidence of thyroid dysfunction. Patients with diabetes, pregnancy, renal and liver impairment were excluded. Fasting Free thyroxine (FT4), Free triiodothyronine (FT3), and thyroid stimulating hormone (TSH) were assessed in all the participants. t-test was used to compare the RA disease characteristics and the thyroid function between early and established RA. $P$ value of $<0.05$ was considered significant.

Results: Rheumatoid arthritis patients had been recruited through a specialized rheumatology clinic, 35 were with new onset rheumatoid arthritis (early RA; ERA of less than a year of RA symptoms onset) and 52 were with established RA (of more than a year of RA symptoms onset). The mean RA duration was $7.4 \pm 2.0$ months for ERA and $96 \pm 92$ months for the established RA group. There were no significant differences in age $(45.76 \pm 2.45$ years for ERA vs, established RA respectively, $\mathrm{p}=0.49$ ), or in gender distribution ( $31 \mathrm{~F}$ and $4 \mathrm{M}$ in ERA vs. $46 \mathrm{~F}$ and $6 \mathrm{M}$ in established $\mathrm{RA}, \mathrm{p}=0.9$ ) between the two groups.

ERA compared to the established RA group had more active RA as manifested by more swollen 28 - joints ( 5.7 vs 1.7 , respectively, $p=0.001$ ), more tender 28 -joints (17 vs 11 , respectively, $p=0.01$ ), higher DAS-28-ESR score (5.8 vs 4.5 , respectively, p0.0001), higher DAS 28-CRP score (5.1 vs. 3.9, respectively, $p=0.001$ ), and longer morning stiffness duration $(p=0.04)$. As well, ERA had lower HDL level (1.4 vs 1.2 , respectively, $\mathrm{p}=0.04$ ). On the other hand, established-RA patients had RA disease onset at an earlier age than the EAR group (36.5 vs 44 years, respectively, $\mathrm{p}=0.02$ )

While the mean TSH, T3 and T4 were within normal range in both groups, there were significant differences in the mean values between ERA and established RA. TSH was $2.12 \pm 1.52$ in ERA vs. $5.8 \pm 8.3$ in established RA (NR:0.27-4.2 mlU/ $\mathrm{L}), \mathrm{p}=0.04$. Mean $\mathrm{FT} 3$ was $4.54 \pm 0.53$ in ERA vs. $3.61 \pm 1.13$ in the established RA (NR: $4-6.8 \mathrm{pmol} / \mathrm{L}$ ), $\mathrm{p}=0.04$. Average FT4 was $17.7 \pm 4.77$ in ERA vs. $15.3 \pm 2.51$ in the established RA (NR: 12-22 pmol/L), $p=0.01$.

Conclusions: RA patients with more than a year of RA symptoms are at a higher risk of silent autoimmune thyroid disease than their age sex matched RA patients with new onset RA; of less than a year of RA symptoms onset. Regular assess ment of thyroid function might be an important part in the routine biochemical and immunological profile screening of RA.

Disclosure of Interest: None declared

DOI: 10.1136/annrheumdis-2018-eular.4245 